\title{
Analisa dan Perancangan Sistem Informasi Elearning Berbasis Web untuk Memantau Aktivitas Belajar Peserta Didik di SMP Fioretti Tigaraksa
}

\author{
Ahmad Takyudin ${ }^{1}$, Husain Faturrahman ${ }^{2}$ Juwono $^{3}$, Muhammad Rizky Julianto ${ }^{4}$, Yulianti ${ }^{5}$ \\ Teknik Informatika, Universitas Pamulang, Tangerang Selatan, Indonesia, 15417 \\ e-mail: 'takyudintakoyaki@gmail.com, ${ }^{2}$ husainfaturahman@gmail.com, ${ }^{3}$ juwonoindonesia@gmail.com, \\ ${ }^{4}$ mrjulianto14@gmail.com, ${ }^{5}$ yulianti@unpam.ac.id
}

Submitted Date: May 31 2021

Revised Date: July $05^{\text {th }}, 2021$
Reviewed Date: June $11^{\text {th }}, 2021$

Accepted Date: July 06 ${ }^{\text {th }}, 2021$

\begin{abstract}
An effective learning system is a learning system that combines collaboration between teachers, students and parents. Many schools are still using traditional methods to manage data and school management, especially in terms of learning materials and managing student grades, so that schools and parents find it difficult to monitor the learning activities of students. For example at SMP Fioretti Tigaraksa, value management and curriculum management are still manual in inputting, the data managed by the school is input in stages without an application or system that regulates and stores it, so that parents, students or teachers find it difficult to monitor the learning activities of participants. such as grades data, curriculum data, learning materials and student attendance, all of these things are still done manually causing the risk of losing data is quite large in each school year. Web-based E-learning Information System can be used as a solution to problems in the field of education, especially to provide materials, student attendance and manage student grades. In this system a prototype is made that will be built in the future, this e-learning system is made to manage value management, attendance and curriculum so that teachers, students and parents of students can access and work together in monitoring student learning activities quickly and easily. efficient. This study provides results to improve student learning activities that can be done wherever they are or do not have to be at school and to connect and establish cooperation between schools, teachers, and parents of students as an important component of education to the student learning process at school.
\end{abstract}

Keywords: Prototyping; E-Learning; Web; Monitoring System

\begin{abstract}
Abstrak
Sistem pembelajaran yang efektif adalah sistem pembelajaran yang memadukan kerjasama antar pengajar/guru, siswa dan orang tua/wali murid. Banyak sekolah yang sampai saat ini masih menggunakan metode tradisional untuk mengelola data dan manejemen sekolah khususnya dalam hal materi pembelajaran dan pengelolaan nilai peserta didik, sehingga sekolah dan orang tua/wali murid kesulitan untuk memantau aktivitas belajar dari peserta didik. Misalnya di SMP Fioretti Tigaraksa, pengelolaan nilai dan manajemen kurikulum masih bersifat manual dalam penginputannya, data-data yang dikelola sekolah di input secara berjenjang tanpa ada sebuah aplikasi atau sistem yang mengatur dan menyimpannya, sehingga orang tua, siswa ataupun guru sulit memantau aktivitas belajar peserta didik seperti data nilai, data kurikulum, materi pembelajaran dan absensi peserta didik, semua hal tersebut masih dilakukan secara manual menyebabkan resiko kehilangan data cukup besar di setiap tahun ajaran. Sistem Informasi E-learning berbasis web dapat digunakan sebagai salah satu solusi atas permasalahan di bidang pendidikan, khususnya untuk memberikan materi, absensi siswa dan mengelola manejemen nilai dari siswa. Dalam sistem ini dibuat sebuah prototipe yang akan di bangun kedepannya, Sistem e-learning ini dibuat untuk mengatur manajemen nilai, absensi dan kurikulum agar guru, siswa dan orang tua/wali murid bisa mengakses dan bekerja sama dalam memantau aktivitas belajar peserta didik secara cepat dan efisien. Penelitian ini memberikan hasil untuk meningkatkan aktivitas belajar siswa yang bisa dilakukan dimanapun mereka berada atau tidak harus disekolah dan untuk menghubungkan dan menjalin kerjasama antar sekolah, guru, dan orang tua siswa sebagai komponen penting pendidikan terhadap proses pembelajaran siswa di sekolah.
\end{abstract}


Kata Kunci: Prototipe; E-learning; Web; Sistem Pemantauan

\section{Pendahuluan}

Komponen penting untuk memajukan sumber daya manusia adalah melalui pendidikan itu sendiri. Untuk mewujudkan pendidikan yang baik kepada siswa tentu saja memerlukan suatu cara untuk mengelola data, nilai dan kurikulum yang merupakan komponen penilaian utama untuk melihat perkembangan siswa secara akademik (Syahputra, 2017). Semua itu juga tidak lepas dari peran pihak sekolah dan orang tua untuk melakukan proses monitoring kepada siswa terutama secara akademik. (Saputra, Sukarsa, \& Bayupati, 2017).

Proses pemantauan atau monitoring yang baik perlu sebuah langkah yang tepat untuk mengidentifikasi sebuah masalah yang timbul dan mencari kaitannya antara kegiatan yang dilakukan dengan ukuran kemajuannya (Kumala, Borman, \& Prasetyawan, 2018). Masalah sistem pemantauan yang dihadapi saat ini adalah hanya terbatas pada proses kegiatan siswa dan guru saja, jarang sekali melibatkan orang tua khususnya dalam proses pembelajaran di luar dari sekolah (Dyah, Muhammad, Setiawansyah, \& Evi, 2020). Cara siswa belajar juga terkadang menjadi terlupakan karena proses monitoring tersebut lebih fokus terhadap hasil belajar saja, dan orang tua juga terkadang sulit mengakses secara penuh kegiatan belajar seperti apa yang siswa tersebut dapatkan saat di sekolah, misalnya seperti nilai akademik, ekstrakulikuler dan absensi siswa (El, 2017). Siswa juga terkadang sering tertinggal pelajaran di sekolah dan itu akan memberikan kesulitan tersendiri terhadap guru, siswa dan orang tua karena materi yang disampaikan guru tidak bisa dia ikuti karena tidak hadir di sekolah (Maulina \& Bernadhed, 2017). Padahal monitoring itu harus digunakan secara baik sehingga bisa menjadi dasar yang berguna dalam evaluasi suatu kegiatan (Suaidah \& Sidni, 2018). Sistem monitoring juga sangat memberikan dampak yang baik bila dilakukan secara efektif (Maulida, Hamidy, \& Wahyudi, 2020).

Proses pembelajaran yang dibuat harus menggunakan cara evaluasi yang didapat dari komunikasi antar pihak sekolah, guru dan orang tua siswa. Guru atau tenaga pendidik bertugas mengatur kurikulum, nilai dan data absensi siswa agar nantinya bisa digunakan sebagai bahan monitoring ke orang tua. Oleh karena itu tujuan dari penelitian ini adalah memberikan hasil untuk meningkatkan aktivitas belajar siswa yang bisa dilakukan di mana pun mereka berada atau tidak harus di sekolah dan untuk menghubungkan dan menjalin kerjasama antara sekolah, guru, dan orang tua siswa sebagai komponen penting pendidikan terhadap proses pembelajaran siswa di sekolah. Diharapkan juga penerapan dari metode yang disarankan tersebut bisa digunakan khususnya dalam membuat dan merancang sebuah aplikasi yang sifatnya fleksibel dan mudah digunakan oleh semua warga sekolah.

Sistem informasi yang baik haruslah menampilkan informasi yang akurat dan telah dilakukan serangkaian pengujian (Ilham, Azmi, Ramadhani, Falah, \& Saifudin, 2021). Pengujian software sebenarnya memiliki tujuan utama yang sederhana, yaitu untuk menjamin software yang dihasilkan sesuai dengan kebutuhan (requirement) yang ditetapkan sebelumnya (Maulana, Kurniawan, Keumala, Sukma, \& Saifudin, 2020). Pada penelitian ini akan dilakukan secara Black Box. Pengujian Black Box yang memiliki arti bahwa pengujian ini hanya memeriksa suatu perangkat lunak dari hasil eksekusinya, tanpa harus tahu mengetahui kode program dan hanya memperhatikan fungsionalnya saja (Nugraha, Aditama, Arrofi, Ahmad, \& Yulianti, 2020).

\section{Metodologi}

\subsection{Alur Penelitian}

Suatu penelitian biasanya dimulai dengan perencanaan yang tepat dengan serangkaian petunjuk yang sistematis dan logis sehingga hasilnya dapat dipertanggung jawabkan.

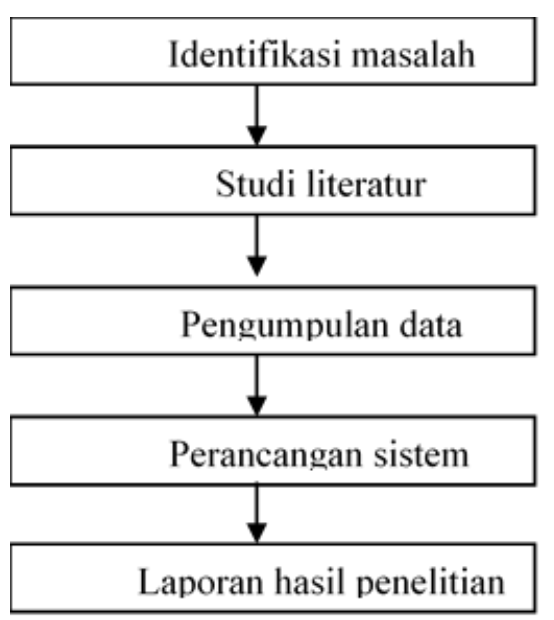

Gambar 1 Alur Penelitian 
Identifikasi masalah merupakan langkah awal yang dilakukan dalam penelitian ini. pada tahap ini diperlukan studi litelatur untuk mempelajari dan memahami teori dan konsep yang relevan dengan masalah yang diteliti, studi litelatur bisa didapat dari jurnal ilmiah, buku, dan referensi lainnya. Hal ini dilakukan untuk dasar dalam melakukan penelitian dan pengembangan penelitian kedepannya.

Pengumpulan data dilakukan untuk mendapatkan data yang akurat dan tepat sesuai dengan subjek yang ditentukan sebelumnya (Ibnu \& Setiawan, 2018). Dalam penelitian ini digunakan beberapa metode yaitu observasi dan wawancara. Observasi dilakukan pada pengamatan langsung terhadap kegiatan akademik sekolah, hal ini bertujuan untuk melihat kondisi dan juga mengamati bagaimana proses pembelajaran dan sistem akademik yang berjalan di SMP Fioretti Tigaraksa. Selanjutnya yaitu wawancara. Pada kegiatan ini dilakukan proses wawancara singkat dengan beberapa warga sekolah seperti kepala sekolah, guru dan staf, serta beberapa murid dan orang tua murid SMP Fioretti Tigaraksa. Hal ini dilakukan untuk mendapatkan informasi langsung dari pihak yang terkait tentang bagaimana proses pembelajaran dan sistem akademik sekolah serta masalah yang dihadapi oleh sekolah tersebut.

Pada tahap perancangan sistem menggunakan diagram UML (Unified Modelling Language) untuk membuat model sistem yang dibuat dalam bentuk aplikasi. Metode prototipe digunakan dalam tahap perancangan sistem karena metode ini tepat digunakan dalam pengembangan sebuah aplikasi atau perangkat lunak secara berkelanjutan. Penelitian ini dimulai dengan pengumpulan kebutuhan yang dibutuhkan oleh pihak sekolah, siswa dan orang tua siswa, proses perancangan atau prototype lalu dibuat setelah mendapatkan evaluasi kembali sebelum diproduksi, semua rancangan tersebut dibuat untuk memenuhi kebetuhan pengguna (Pressman, 2012).

\subsection{Analisis Kebutuhan Fungsional}

Kebutuhan fungsional merupakan data yang digunakan untuk dimasukkan dalam sebuah fungsi dari sistem yang dibuat. Berikut adalah kebutuhan fungsional:

1. Staf TU (admin)

Staf TU merupakan aktor yang dapat mengelola data akademik sekolah berupa jadwal pelajaran, data siswa dan orang tua siswa, guru, wali kelas, kegiatan ekstrakulikuler, absensi guru, mata pelajaran, dan melakukan proses cetak laporan akademik.

2. Kepala Sekolah

Kepala sekolah merupakan aktor yang dapat melihat laporan akademik sekolah berupa jadwal pelajaran, data siswa dan orang tua siswa, guru dan wali kelas, data kegiatan ekstrakulikuler, dan absensi guru di sekolah.

3. Wali Kelas

Wali kelas merupakan aktor yang dapat melihat jadwal pelajaran, mengelola absensi siswa, mengelola data prestasi siswa, mengelola ekstrakulikuler, melihat nilai siswa dan melakukan cetak raport siswa.

4. Guru

Guru merupakan aktor yang dapat melihat jadwal pelajaran, mengelola data nilai siswa, dan mengelola data materi pembelajaran dan kurikulum

5. Orang Tua Siswa

Orang tua siswa merupakan aktor yang dapat melihat informasi wali kelas, melihat informasi guru, melihat nilai siswa/anaknya, melihat jadwal pelajaran siswa, melihat absensi siswa, melihat ekstrakulikuler siswa, dan melakukan cetak raport siswa.

6. Siswa

Siswa/peserta didik merupakan aktor yang dapat melihat rangkuman materi pembelajaran dan kurikulum, melihat nilai siswa, melihat jadwal pelajaran, melihat absensi siswa, melihat ekstrakulikulee, dan melakukan cetak raport siswa.

\subsection{Perancangan Sistem}

\section{A. Use Case Diagram}

Pada tahap perancangan sistem ini dibuat sebuah kebutuhan fungsional yang digambarkan dalam Use Case Diagram sehingga diketahui peran masing-masing dari para actor di dalam sebuah sistem, pada sistem ini actor saling berhubungan satu sama lain karena mekanisme data yang saling berhubungan dan saling terkait. 


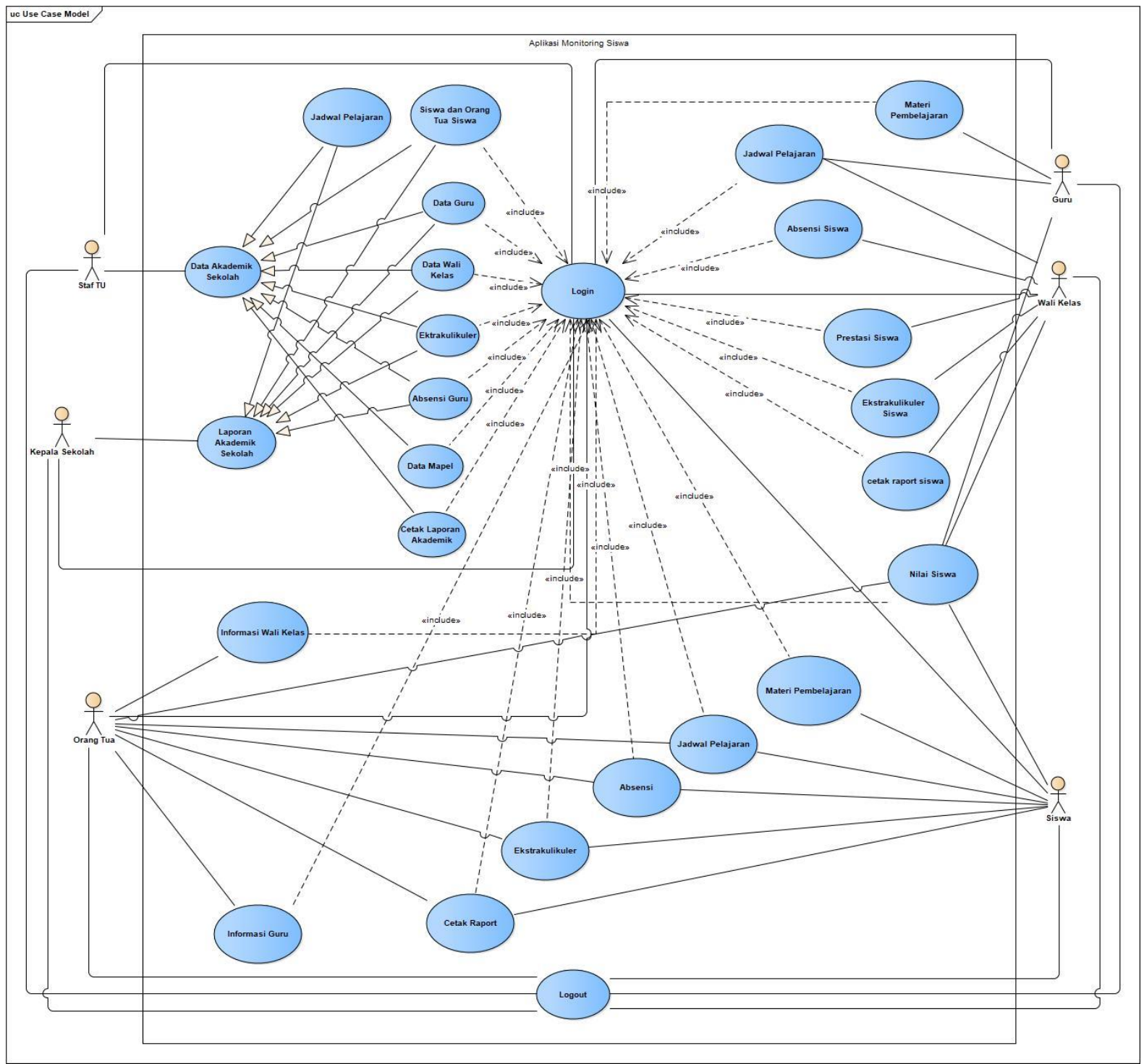

Gambar 2 Use Case Diagram Aplikasi Monitoring Siswa

\section{B. Activity Diagram}

Activity diagram berfungsi menunjukkan proses yang terjadi di dalam sistem. Membuat activity diagram dari beberapa actor di dalam sistem yang menunjukkan keterkaitan antar actor, hal ini diperlukan supaya mekanisme data saling terhubung dan bisa dilakukan koreksi data antar masing-masing actor. Perancangan sistem pada intinya dimulai dari menu login yang data usernya didapat dan dikelola oleh Staf TU, kemudian masing-masing actor bisa di tetapkan oleh Staf TU untuk masuk ke halaman sistem dan melakukan kebutuhan fungsionalnya masing - masing.

\section{Activity Diagram untuk Login}

Pertama user akan memasukkan user id berupa alamat email dan password, lalu sistem akan membaca atau request user id dan password tersebut, selanjutnya dilakukan proses validasi dengan mengirimkan data user ke database, jika data benar maka database akan melakukan response atau mengembalikan data untuk ditampilkan, kemudian dilakukan pengecekan di sistem melalui fungsi pengkondisian. Jika user valid maka tampilkan menu utama, jika tidak tampilkan pesan kesalahan. 


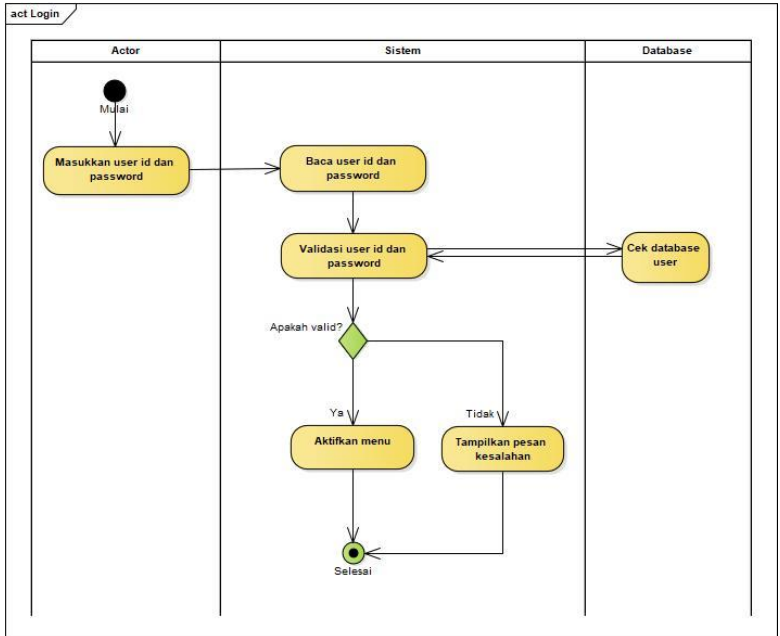

Gambar 3 Activity Diagram Login

\section{Activity Diagram untuk Logout}

Langkah awal yaitu user memilih menu Logout yang ada di dalam aplikasi, lalu akan muncul pesan logout/keluar halaman dashboard, pada bagian ini sistem akan melakukan pengecekan menggunakan fungsi pengkondisian, jika mengklik iya, maka user akan keluar halaman dashboard, jika tidak maka perintah akan dibatalkan dan tetap berada di halaman dashboard.

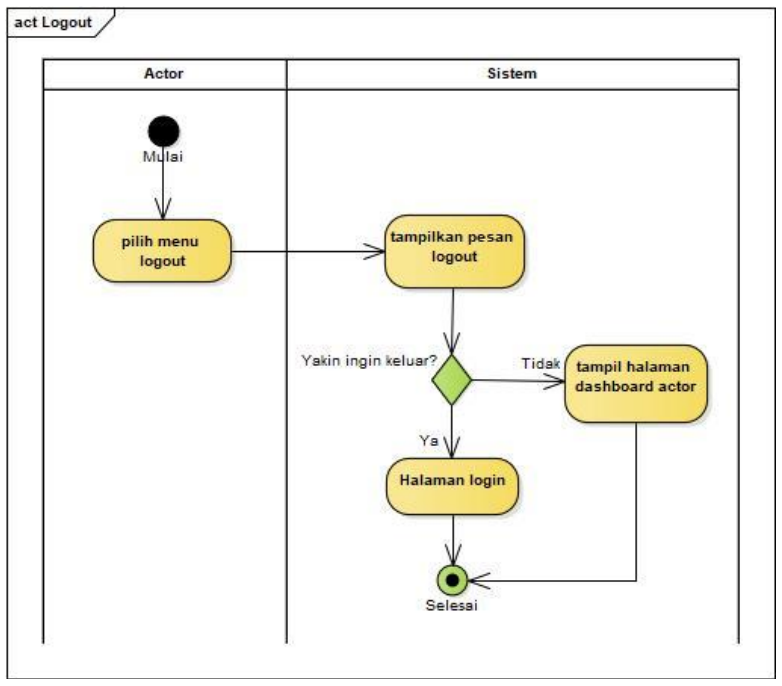

Gambar 4 Activity Diagram Logout

\section{Activity Diagram untuk Data Akademik Sekolah (Staf TU)}

Pertama user akan masuk sebagai admin, lalu akan masuk ke dalam sistem menu pengelolaan data akademik, user memilih kelola data akademik, lalu menekan tombol simpan, hapus atau edit terhadap data, kemudian sistem akan menyimpan ke database sekaligus menampilkannya ke dalam sistem. Lalu pilih menu cetak laporan akademik untuk mencetaknya.

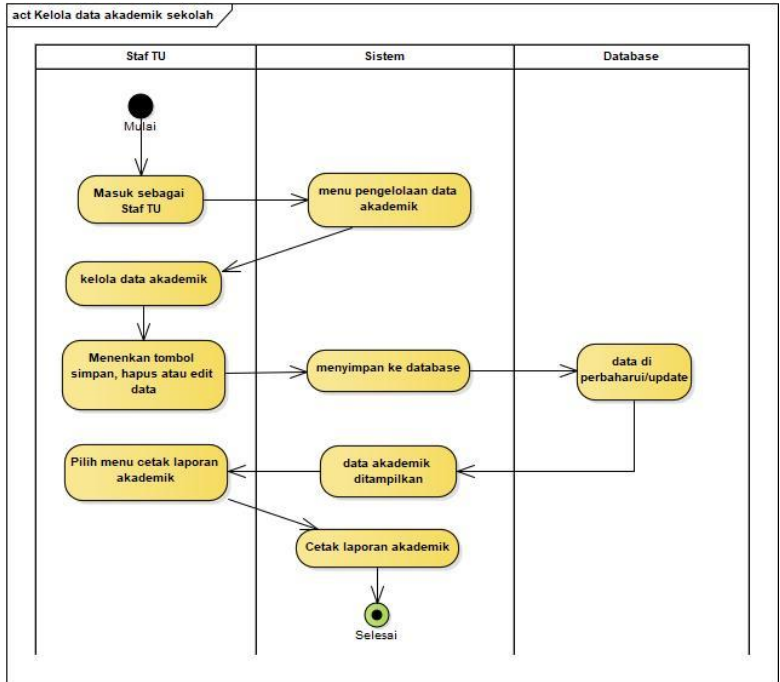

Gambar 5 Activity Diagram Mengelola Data Akademik Sekolah

\section{Activity Diagram untuk Laporan Akademik} Sekolah (Kepala Sekolah)

User berupa Staf TU melakukan input data akademik sekolah, setelah data sudah di input maka kepala sekolah bisa melakukan pengecekan dan melihat data tersebut, kemudian sistem akan menampilkan data, lalu kepala sekolah bisa melihat data akademik berupa jadwal pelajaran, absensi guru, dan sebagainya.

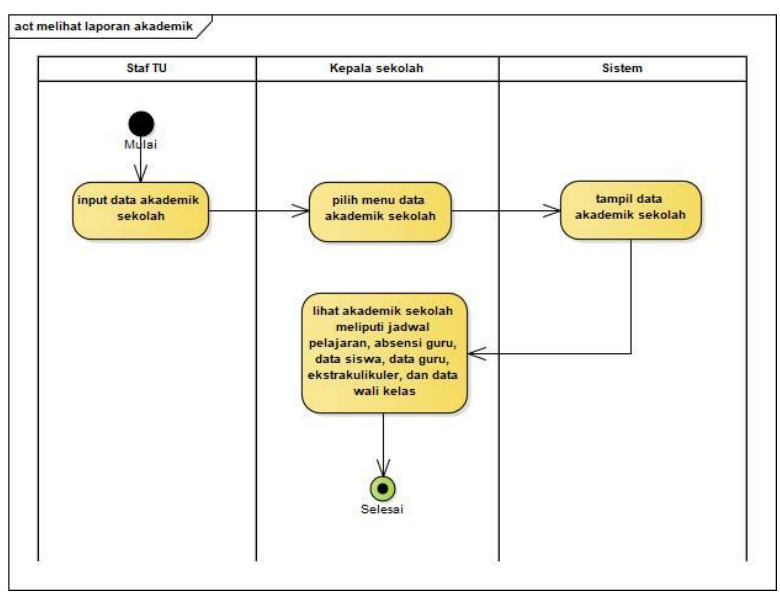

Gambar 6 Activity Diagram Mengelola Laporan Akademik Sekolah

\section{Activity Diagram untuk Data Materi Pembelajaran (Guru)}

Pertama user berupa Staf TU akan melakukan input data mapel, lalu guru bisa melakukan input kurikulum pembelajaran dan rangkuman materi pembelajaran dengan cara masuk menggunakan akun guru, sistem akan menampilkan data yang disimpan oleh guru tersebut, database akan 
mengeksekusi dengan melakukan response berupa tampil data materi pembelajaran, pilih tambah, hapus atau upload materi pembelajaran, kemudian sistem akan menyimpan request ke dalam database dan melakukan eksekusi yang hasilnya berupa tampil data yang di update, setelah itu siswa akan bisa melihat materi pembelajaran di aplikasi tersebut yang dibuat oleh guru sebelumnya.

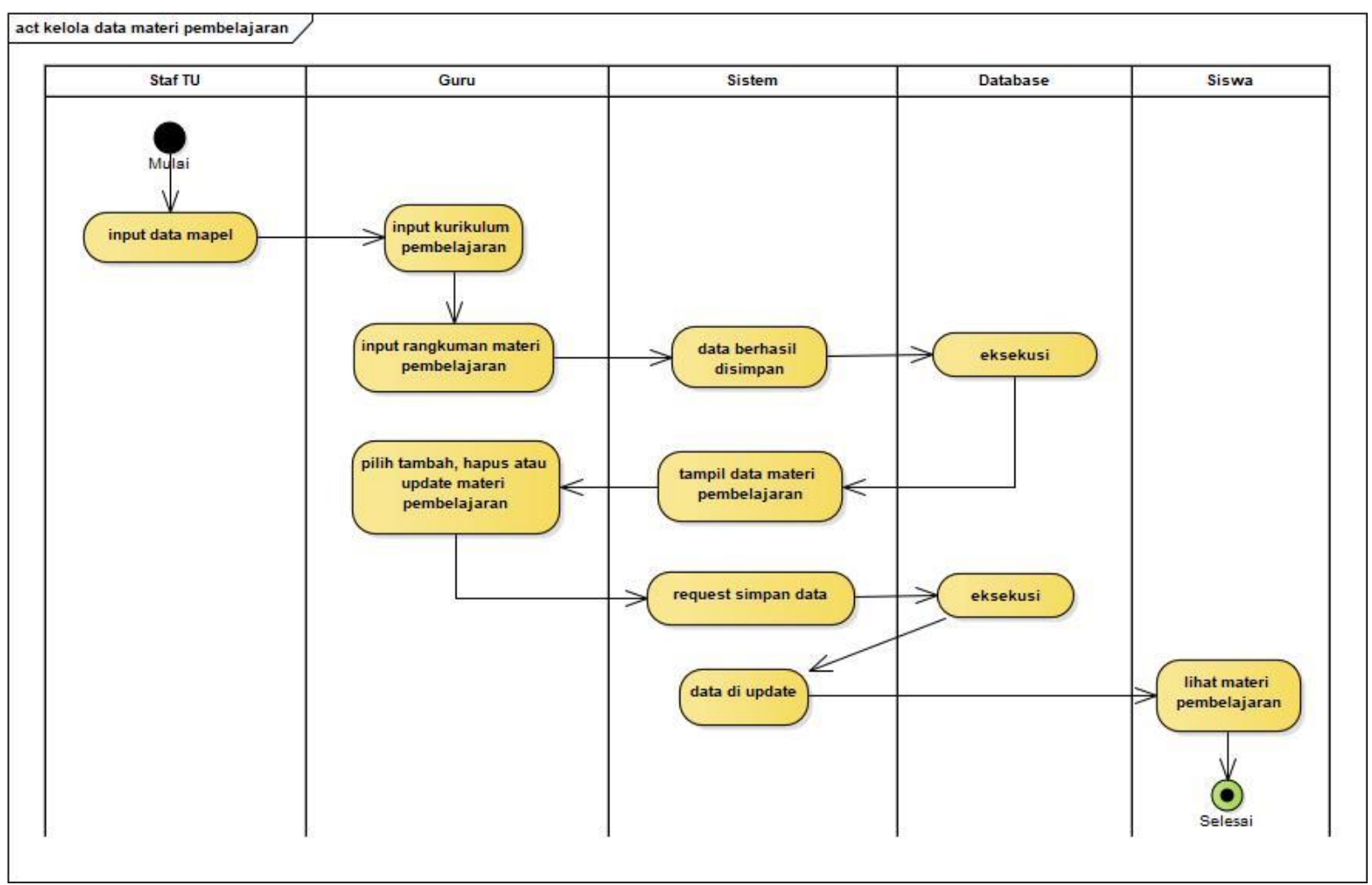

Gambar 7 Activity Diagram Mengelola Data Materi Pembelajaran

\section{Activity Diagram untuk Cetak Raport Siswa (Wali Kelas)}

User berupa Staf TU harus melakukan input data siswa terlebih dahulu, lalu guru bisa melakukan proses menginputan nilai siswa, sedangkan dari Wali Kelas bisa melakukan menginputan absensi siswa, ekstrakulikuler, dan data akademik siswa, kemudian sistem akan menampilkan data akademik tersebut, lalu pilih cetak raport siswa, sistem akan melakukan konfirmasi menggunakan fungsi pengkondisian, jika ingin mencetak pilih Ya, maka akan tampil halaman preview raport siswa, pilih cetak dan selanjutnya raport akan tercetak. Jika pilih Tidak, maka akan dikembalikan ke halaman data akademik siswa.

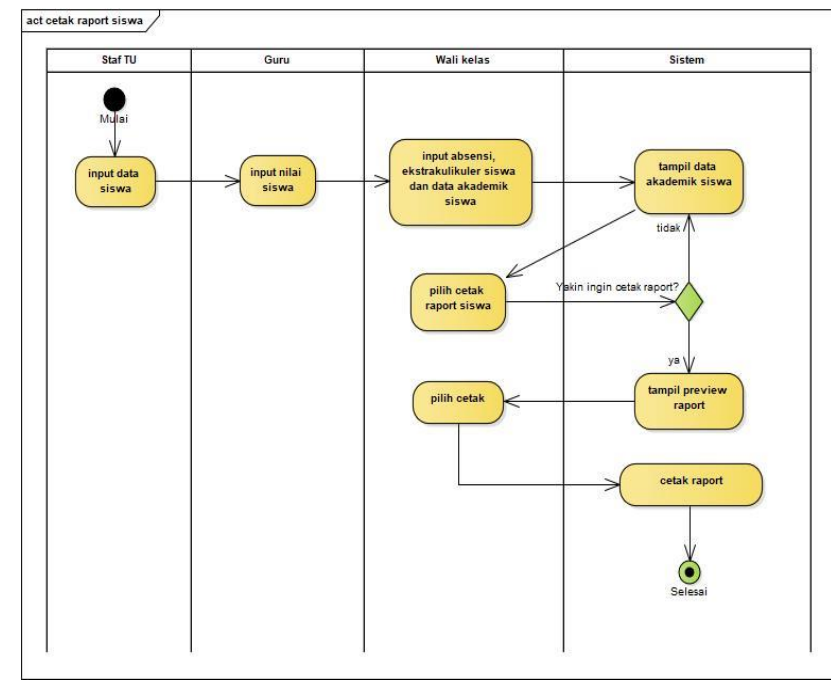

Gambar 8 Activity Diagram Cetak Raport Siswa

Activity Diagram untuk Informasi Wali Kelas (Orang Tua Siswa)

Pertama user berupa Staf TU akan melakukan penginputan data wali kelas, lalu orang tua siswa bisa memilih menu informasi wali kelas, sistem akan menampilkan halaman informasi wali kelas, lalu orang tua bisa memilih bagian melihat 
informasi wali kelas, lalu data akan tampil di sistem

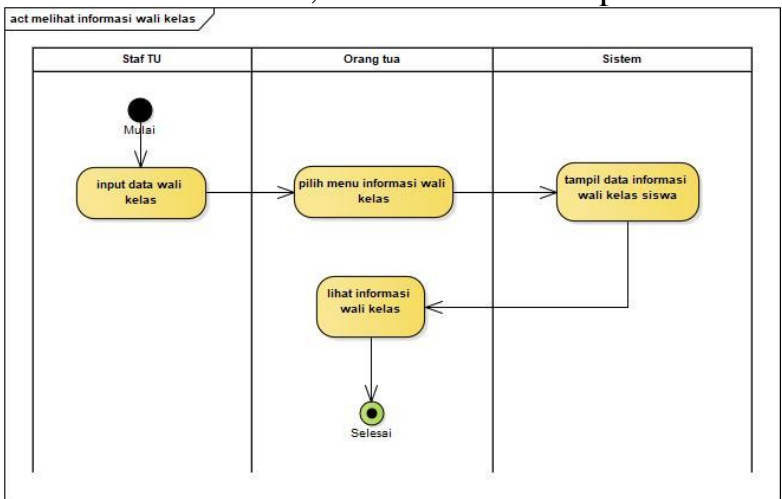

Gambar 9 Activity Diagram Melihat Informasi Wali Kelas

\section{Activity Diagram untuk Materi Pembelajaran} dan Kurikulum (Siswa)

User berupa Guru harus melakukan input materi pembelajaran dan kurikulum di dalam sistem terlebih dahulu, lalu siswa bisa memilih menu rangkuman materi pembelajaran, sistem akan menampilkan halaman rangkuman materi pembelajaran, kemudian siswa bisa memilih hari, tanggal dan tahun serta mata pelajaran yang ingin dia lihat, sistem akan menampilkan pelajaran pilihan siswa, dan siswa bisa melihat materi pembelajaran tersebut di sistem.

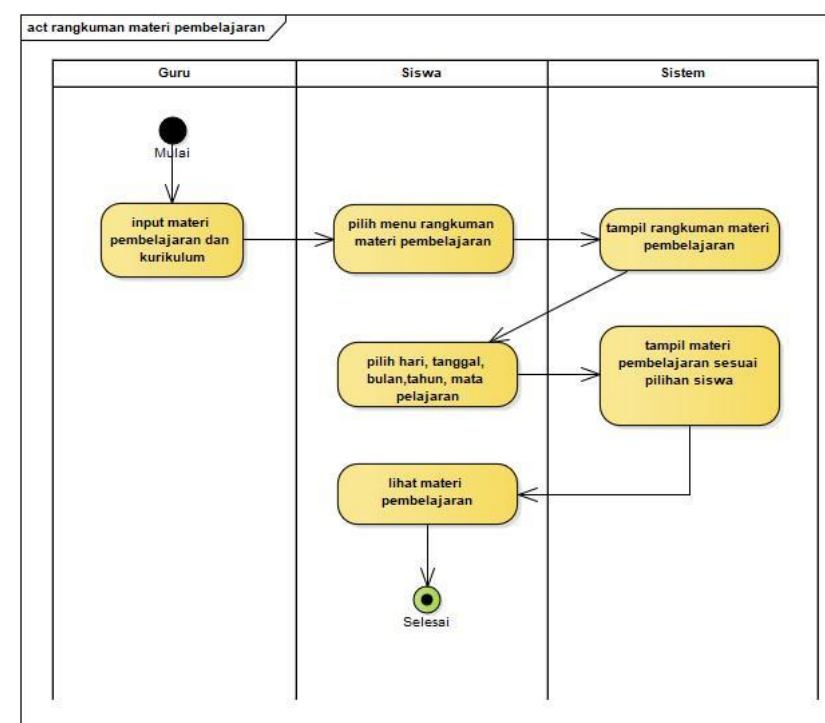

Gambar 10 Activity Diagram Melihat Materi Pembelajaran dan Kurikulum

\section{Activity Diagram untuk Nilai Siswa (Guru)}

Staf TU harus melakukan penginputan data siswa terlebih dahulu, lalu guru bisa memilih menu kelola nilai siswa, dan melakukan input kurikulum, kemudian sistem akan menampilkan data kurikulum, kemudian pilih input nilai siswa, sistem akan mengirim request ke dalam database dan mencari data kurikulum dan data siswa yang di input, lalu database akan melakukan response dan sistem akan menampilkan data nilai siswa, guru bisa menambah, hapus dan update nilai siswa, request disimpan di database, lalu sistem akan menampilkan nilai siswa yang berhasil di simpan atau di input tersebut.

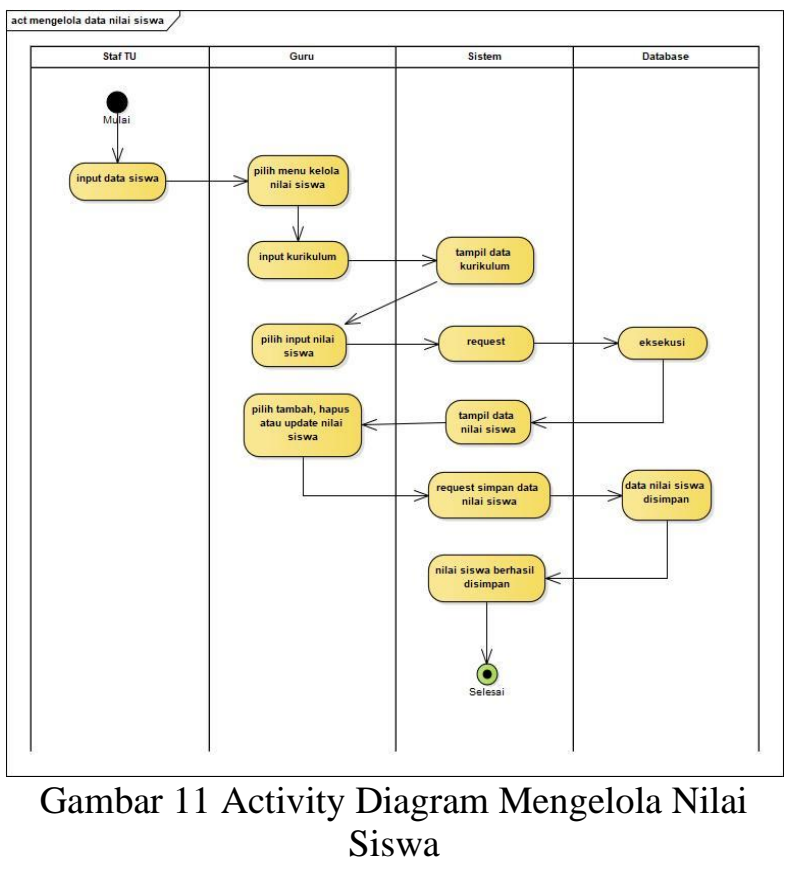

\section{Activity Diagram untuk Nilai Siswa (Siswa)}

Pertama guru harus sudah selesai melakukan proses penginputan nilai siswa di dalam sistem, kemudian orang tua dan wali kelas bisa memilih menu lihat nilai siswa, maka sistem akan menampilkan data tersebut, dan orang tua ataupun wali kelas bisa melihat data nilai siswa tersebut.

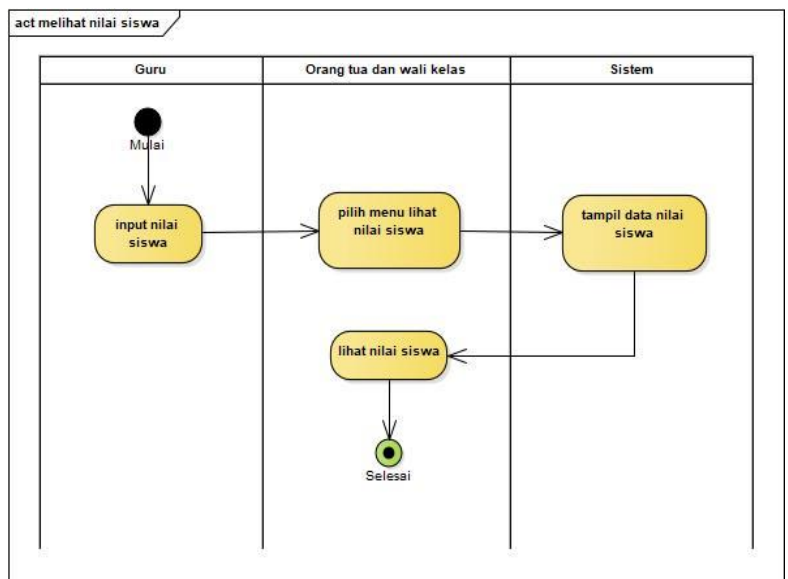

Gambar 12 Activity Diagram Mencetak Nilai Siswa 


\section{Hasil dan Pembahasan}

Dilihat dari hasil analisis sistem belajar mengajar di sekolah tersebut sangat antusias dalam hal perkembangan teknologi akademik sekolah. Pihak sekolah juga sudah memiliki beberapa fasilitas yang mendukung untuk menunjang implementasi sistem seperti sudah adanya perangkat teknologi komputer yang memadai. Melihat situasi sekolah seperti ini dan dengan dibuatnya sistem tersebut membuat sekolah menjadi gencar dan antusias dalam meningkatkan kualitas pendidikan menjadi lebih baik. Namun demikian, meskipun sekolah telah melakukan program - program terbaik untuk meningkatkan kualitas pendidikan untuk siswa belum tentu menjamin keberhasilan kegiatan tersebut terutama dalam hal proses pembelajaran dan komunikasi dengan orang tua siswa. Dengan demikian, perlu adanya sistem blended learning antar sistem tatap muka di sekolah dan sistem monitoring secara online melalui perancangan sistem informasi yang dibuat ini, agar data yang dikelola sekolah bisa di manajemen dengan baik namun di sisi lain sekolah bisa menjalin hubungan komunikasi dengan orang tua siswa mengenai perkembangan akademik peserta didik di sekolah.

Sistem kebutuhan fungsional juga di atur agar user yang tidak dikenal dan tidak ditambahkan oleh Staf TU, tidak akan bisa masuk dan melakukan fungsi tersebut. Data user harus ditambah dan dikelola oleh Staf TU agar warga sekolah termasuk siswa bisa mengelola atau melihat data akademik sekolah yang dibuat. Sistem user juga dibuat saling terkait agar terjadi singkronisasi data antar user dan data bisa dipantau secara berkala dan berjenjang. Misalnya saat melakukan pencetakan raport siswa. Pertama, data siswa dan orang tua harus di input ke dalam sistem, lalu selanjutnya user guru harus melakukan proses penginputan nilai siswa. Setelah itu wali kelas baru bisa melakukan proses penginputan data absensi siswa, prestasi siswa, ekstrakulikuler siswa, dan data akademik lainnya secara personal.

Dan akhirnya orang tua siswa, siswa ataupun wali kelas bisa melakukan pencetakan raport akademik siswa. Khusus user guru memiliki fungsi yang terbatas yaitu hanya bisa melakukan penginputan nilai siswa, input data kurikulum dan materi pembelajaran, serta hanya bisa melihat jadwal pelajaran yang berlangsung. Hal ini dirancang ke sistem karena peran guru cukup signifikan dalam proses pembelajaran, guru harus mengajar secara langsung ke siswa, sehingga beban penginputan data tidak terlalu banyak dan sistem dibuat agar bisa fokus kepada fungsi akademik siswa.

\section{Kesimpulan}

Proses pembelajaran berbasis E-learning dengan sistem pemantauan yang baik sangat diperlukan dalam proses pembelajaran. Dengan ada sistem informasi berbasis E-learning dengan sistem monitoring proses belajar mengajar tetap bisa berjalan walaupun guru, wali kelas dan siswa berhalangan hadir dan membuat siswa dan guru tidak ada batasan waktu untuk belajar. Dari sisi orang tua siswa juga bisa memantau kegiatan anak peserta didiknya di sekolah sekaligus bekerja sama dengan wali kelas dan pihak sekolah lainnya untuk meningkatkan perkembangan siswa dalam belajar. Penelitian ini menghasilkan prototipe sistem berbasis web dan menyediakan berbagai macam fitur untuk menunjang kegiatan akademik di sekolah sehingga proses e-learning dan pemantauan bisa berjalan beriringan.

\section{Saran}

Untuk penelitian selanjutnya diharapkan dapat mengembangkan sistem berbasis web ini ke dalam platform yang berbeda seperti android dan IOS sehingga lebih memudahkan siswa mengaksesnya dimanapun dan kapanpun melalui perangkat mobile. Selain itu bisa juga ditambahkan fitur chat, poling, menu pembayaran sekolah atau fitur menarik lainnya agar lebih menarik minat belajar siswa dan memudahkan orang tua siswa. Dari segi pihak sekolah sebaiknya menggunakan sistem ini untuk memantau proses perkembangan siswa kemudian memetakannya dalam sebuah data yang bisa dievaluasi setiap tahun ajaran, sehingga manajemen data yang di input bisa dikelola dengan maksimal di database dan digunakan di masa sekarang atau masa depan.

\section{Referensi}

Dyah, A. M., Muhammad, B., Setiawansyah, \& Evi, D. (2020). Sistem Monitoring Kegiatan Akademik Siswa Menggunakan Website. Jurnal Tekno Kompak, Volume 14, No.2, pp 98-101.

El, I. k. (2017). Belajar Dan Pembelajaran. Yogyakarta: Pustaka Pelajar.

Ibnu, H., \& Setiawan, A. (2018). Analisis dan Perancangan Sistem E-learning Berbasis Web Pada SMA Negeri 4 Kota Jambi. Jurnal Manajemen Sistem Informasi, Volume 3, No.4, pp 1255-1260.

Ilham, A. A., Azmi, A., Ramadhani, A. R., Falah, D. F., \& Saifudin, A. (2021). Pengujian Sistem Informasi Parkir PT KISP Berbasis Desktop 
dengan Metode Black-Box. Jurnal Informatika Universitas Pamulang, 6(1), 96-101. doi:10.32493/informatika.v6i1.8547

Kumala, A. E., Borman, R. I., \& Prasetyawan, P. (2018). Sistem Informasi Monitoring Perkembangan Sapi Di Lokasi Uji Performance (Studi Kasus: Dinas Peternakan dan Kesehatan Hewan Provinsi Lampung). Jurnal Tekno Kompak, Volume 12.1, pp 5-9.

Maulana, A., Kurniawan, A., Keumala, W., Sukma, V. R., \& Saifudin, A. (2020). Pengujian Black Box pada Aplikasi Penjualan Berbasis Web Menggunakan Metode Equivalents Partitions (Studi Kasus: PT Arap Store). Jurnal Teknologi Sistem Informasi dan Aplikasi, 3(1), 50-56. doi:10.32493/jtsi.v3i1.4307

Maulina, D., \& Bernadhed. (2017). Perancangan Sistem Informasi E-Learning Pada SMK Syubbanul Wathon Tegalrejo. Jurnal Ilmiah DASI Data Manajemen dan Teknologi Informasi, 8.

Nugraha, B. F., Aditama, F., Arrofi, M., Ahmad, S. U., \& Yulianti, Y. (2020). Pengujian Black Box pada Aplikasi Penghitungan Parkir Swalayan ADA Menggunakan Teknik Equivalence Partitions. Jurnal Informatika Universitas Pamulang, 5(2), 146-151. doi:10.32493/informatika.v5i2.5350

Pressman, R. S. (2012). Rekayasa Perangkat Lunak Pendekatan Praktisi (Vol. Edisi 7). Yogyakarta: Andi.

Saputra, P. S., Sukarsa, I. M., \& Bayupati, I. P. (2017). Sistem Informasi Monitoring Perkembangan Anak Di Sekolah Taman Kanak-Kanak Berbasis Cloud. Lontar Komputer, Volume 8 (2), pp. 112-123.

Suaidah, S., \& Sidni, I. (2018). Perancangan Monitoring Prestasi Akademik dan Aktivitas Siswa Menggunakan Pendekatan Key Performance Indicator (Studi Kasus SMA N 1 Kalirejo). Tekno Kompak, Volume 12.2, pp 62-67.

Syahputra, F. (2017). Sistem Informasi E-Learning di Sekolah. Nusa Mandiri, 60-65. 